\title{
APLICAÇÃO DA FILOSOFIA LEAN SERVICE PARA A OTIMIZAÇÃO DO PROCESSO DE SERVIÇO DE UMA EMPRESA JÚNIOR DE CONSULTORIA
}

\section{LEAN SERVICE PHILOSOPHY APPLICATION FOR THE SERVICE PROCESS OPTIMIZATION OF A JUNIOR ENTERPRISE}

\author{
L. BENINI ${ }^{1, *}$ e F. R. R. BATISTA ${ }^{1}$ \\ ${ }^{1}$ Universidade Federal de Viçosa, Departamento de Engenharia de Produção e Mecânica, Viçosa, Minas Gerais, Brasil
}

${ }^{*}$ Autor correspondente. Universidade Federal de Viçosa, Departamento de Engenharia de Produção e Mecânica, Viçosa, Minas Gerais, Brasil, Phone: +55 31

36126500

Endereço de e-mail: lucasbenini@gmail.com (L. Benini).

\begin{tabular}{l} 
A R T I C L E I N F O \\
\hline Article history: \\
Received 2019-01-03 \\
Accepted 2019-08-15 \\
Available online 2019-08-20 \\
pa lavras-chave \\
Lean Service \\
Redução de desperdícios \\
Empresa Júnior \\
ke y words \\
Lean Service \\
Waste Reduction \\
Junior Enterprise
\end{tabular}

\begin{abstract}
R E S U M O
O setor de serviços tem se tornado cada vez mais um campo estratégico para a economia brasileira. Deste modo, as empresas têm buscado, progressivamente, formas de melhorar e otimizar seus processos, tornando-as mais competitivas. Neste contexto, este trabalho tem como objetivo a aplicação do lean service em uma Empresa Júnior de Consultoria, visando a otimização de seu processo de serviços por meio da redução de desperdícios e agregação de valor ao seu serviço. Realizou-se o diagnóstico inicial da empresa, prosseguindo-se com o estudo de seu processo de prestação de serviços de consultoria e construção dos mapas de fluxo de valor (atual e futuro), bem como a identificação de desperdícios. Por meio das análises realizadas foi possível identificar os pontos críticos do processo e propor melhorias para um tipo de serviço que exige alta participação dos clientes, tornando as análises mais complexas.
\end{abstract}




\section{INTRODUÇÃO}

No Brasil, o setor de serviços é o de maior participação na economia. De acordo com dados do IBGE, o setor representou $75,2 \%$ do valor adicionado do PIB brasileiro no $4^{\circ}$ trimestre de 2017. Neste contexto, percebe-se que este é um campo estratégico para a economia brasileira e que merece destaque no que tange a melhoria de seus resultados. Diante de tal cenário, progressivamente, as empresas têm buscado formas de melhor e otimizar seus processos, tornando-as mais competitivas no mercado. Assim, novas ferramentas e metodologias de gestão vem surgindo com o objetivo de potencializar os resultados de diferentes tipos de organizações, como é o caso do lean service.

Se no século $\mathrm{XX}$, no auge das indústrias, o lean manufacturing ficou em evidência como uma metodologia capaz de eliminar os desperdícios nas manufaturas e agregar valor aos seus produtos; atualmente, o lean service, o qual aplica os princípios do pensamento enxuto no setor de serviços, vem surgindo como uma metodologia que possui o mesmo potencial, embora os estudos na área ainda sejam incipientes.

O lean service é aplicável nos mais variados tipos de empresas, como empresas de serviços de tecnologia da informação (Fortes, 2010), corretoras de seguros (Roman et al., 2013), centros de serviços compartilhados (Sum, 2016), dentre outras. Neste âmbito, identificou-se a oportunidade de aplicação dessa metodologia para a melhoria do processo de serviço de uma empresa júnior de consultoria, definida como uma organização sem fins lucrativos gerida por estudantes de um determinado curso superior.

O Movimento Empresa Júnior (MEJ) surgiu na França, em 1967, a partir da necessidade dos alunos de se integrarem ao mercado de trabalho, indo além da teoria exposta em sala de aula, colocando em prática conhecimentos acadêmicos com clientes no mercado. Segundo dados da Brasil Júnior, Confederação Brasileira de Empresas Juniores, em 2016, a rede contou com 15.777 empresários juniores, sendo o PIB júnior de $\mathrm{R} \$$ 11.096.620,77, representando assim um movimento de impacto em todo o país. Para gerar todos esses resultados, o movimento é apoiado em três pilares: Gestão, Projetos e Cultura Empreendedora. O pilar Gestão busca criar equipes de alta performance, capacitadas para a gestão e que alcance metas consistentemente. Já o pilar Projetos tem o intuito de capacitar os membros para realização de mais projetos, atingindo maior abrangência na sociedade, e ao mesmo tempo, desenvolvendo melhores soluções para o mercado. Por fim, o pilar de Cultura Empreendedora, visa criar líderes dotados de postura empreendedora, compromisso com resultados, transparência e sinergia. Assim, percebe-se que é fundamental que todos os processos da empresa estejam alinhados a tais objetivos e que, acima de tudo, agreguem valor aos serviços prestados, visto que um dos principais propósitos do movimento é impactar a sociedade oferecendo soluções inteligentes ao mercado.

Nesta conjuntura, o presente trabalho tem por finalidade aplicar o Lean Service na Empresa Júnior em estudo, visando contribuir para a melhoria de seu processo de serviços, por meio da agregação de valor ao processo e eliminação de desperdícios durante a prestação de serviços. Como objetivos específicos tem-se: a identificação do fluxo de valor da empresa; a identificação de gargalos do processo de prestação de serviços; o levantamento das causas dos principais desperdícios e a proposição de melhorias para o processo de serviço da empresa.

\section{O SETOR DE SERVIÇOS}

O conceito de serviços é definido de várias formas na literatura. Hill (1977) apud Fortes (2010), sugere que serviço é uma alteração nas condições de uma pessoa ou bem pertencente a uma entidade econômica, resultante da atividade de alguma outra entidade, com a aprovação da primeira. Fonseca (2012), destaca que serviços são intangíveis, não podendo ser experimentados antes de serem comprados; perecíveis, no sentido de que são consumidos à medida que vão sendo produzidos, não sendo passíveis de serem armazenados, como no caso de produtos físicos; e principalmente possuem a presença do cliente na entrega do mesmo, ou seja, a sua produção e o seu consumo são simultâneos, o que se traduz num potencial grau de imprevisibilidade no output do processo da prestação.

Um ponto importante a ser considerado em operações de serviços é a definição de qualidade para o cliente. Para Suraman et al. (1985) apud Fortes (2010), destaca-se que em serviços, o cliente avalia simultaneamente o processo de serviço e seus resultados, tornando-se fundamental investir na melhoria de tais processos. Os mesmos autores identificaram dez categorias (dimensões) para definir qualidade em serviços: tangibilidade (evidências físicas do serviço (instalações físicas, aparência dos funcionários, equipamentos utilizados na prestação do serviço), confiabilidade (prestação do serviço com confiança, exatidão e prazo cumprido), receptividade (vontade e pronto atendimento do funcionário para prestar o serviço), credibilidade (seriedade e honestidade, sendo relevante a reputação da companhia), conhecimento do cliente (esforço para a compreensão das necessidades do consumidor), competência (habilidade e conhecimento para o desempenho do serviço), acesso (facilidade para contato com o prestador do serviço), cortesia (polidez, respeito, consideração e tratamento amistoso no contato pessoal), comunicação: manter o cliente informado e um canal aberto para ouvi-lo), segurança (ausência de perigos, riscos ou dúvidas, envolvendo desde segurança física até a segurança e privacidade das informações).

De modo geral, um serviço é efetivo quando suas saídas agregam valor para o cliente (Fortes, 2010), sendo o "valor" determinado a partir do tipo de serviço prestado. A percepção de qualidade por clientes de serviços de consultoria, o qual é tratado neste estudo, perpassa várias das características citadas.

\subsection{Serviços de Consultoria}

A consultoria pode ser definida como a prestação de serviços em determinada área por profissionais qualificados e especialistas no tema. Kubr (1986), destaca que a consultoria de organização é um serviço que busca auxiliar na análise e solução de problemas de ordem prática e difundir técnicas de gestão bem-sucedidas, nos diversos setores da economia.

O funcionamento de um serviço de consultoria está relacionado às necessidades dos clientes que precisam ser atendidas, mas de forma geral, inicia-se com um diagnóstico da empresa cliente, buscando-se levantar os principais problemas que a mesma enfrenta, bem como as causas raízes desses problemas. A partir disso, é possível identificar soluções e levantar ações, para que o consultor possa desenvolver, implantar e viabilizar projetos de acordo com a necessidade 
específica de cada cliente (Moser, 2009).

Geralmente, os resultados de um serviço de consultoria são obtidos, ou podem ser enxergados, a longo prazo, visto que diz respeito à conquista de um objetivo, ao atingimento de um estado futuro da empresa cliente. Além disso, um ponto importante a ser destacado é que os consultores não trabalham de forma isolada, necessitando assim da interação constante com o cliente, ao longo da realização do projeto.

De forma geral, deve-se salientar que os serviços de consultoria fornecem um mix de conhecimentos, práticas, ferramentas e metodologias ao cliente, mas, acima de tudo, funcionam como catalisadores entre o planejamento traçado e os objetivos alcançados pela organização). Entretanto, não são tomadores de decisões, de outro modo, a consultoria é um processo iterativo que visa auxiliar a organização, mas sem possuir o controle da situação.

\subsection{Lean thinking}

As origens do lean thinking ou pensamento enxuto, remontam ao período Pós Segunda Guerra Mundial, quando o executivo da Toyota Taiichi Ohno iniciou, na década de 50, a criação e implantação de um sistema de produção cujo principal foco era a identificação e a posterior eliminação de desperdícios, com o objetivo de reduzir custos e aumentar a qualidade e a velocidade de entrega do produto aos clientes (Silva et al. , 2008). Posteriormente, em 1990, surgiu o conceito lean manufacturing ou produção enxuta, usado no meio científico pela primeira vez pelos autores Womack e Jones (1990) em seu livro “A máquina que mudou o mundo". Segundo Womack e Jones (2004), o termo "enxuta" se deve pela redução das quantidades de diversos fatores na forma de gerir a produção se comparada ao sistema de produção em massa, como funcionários, espaço para fabricação, ferramental, tempo de produção, tempo de planejamento, entre outros.

Esta ampliação da produção enxuta foi denominada de mentalidade enxuta (lean thinking) pelos referidos autores, que também apresentam em seu segundo livro, uma abordagem orientada para sua implementação em empresas (Bulhões, 2009). Com isso, o termo deixou de se restringir à Toyota e à produção e passou a ser utilizado nas mais diversas áreas empresariais e nos diversos setores do mercado, como a área de serviços (lean service), administrativa (lean office), ambiental (lean environment), logística (lean logistics), entre outros.

\subsection{A filosofia lean aplicada à serviços: lean service}

O setor de serviços é um dos cernes da economia mundial e seu bom desempenho tem se mostrado cada vez mais crítico para que esta se mantenha sadia e funcional (Fitzsimmons e Fitzsimmons, 2005). Progressivamente, os clientes têm exigido mais qualidade, redução de custos, flexibilidade, produtividade e redução de lead times dos serviços prestados pelas empresas dos mais variados setores. Womack et al. (1998), destacam que, assim como na manufatura, o cliente não quer pagar pelo desperdício ou pela falta de eficiência da empresa. Sendo assim, é fundamental a racionalização de recursos via redefinição de processos. Neste contexto, as organizações de serviço estão dirigindo a atenção ao setor de manufatura para aprender e implementar técnicas e métodos, antes focados exclusivamente a esta área, como é o caso do lean manufacturing. Assim, o lean service pode ser definido como uma metodologia que visa apoiar empresas/processos de serviços a melhorar seu nível de excelência, de forma extremamente focada no cliente final, apoiada nos princípios do pensamento enxuto.

Entretanto, a aplicação dos métodos e ferramentas lean no setor de serviços não é trivial, visto as particularidades do setor, que possui características distintas do setor de manufatura. Uma das principais dificuldades a este respeito é o caráter único das operações de serviços, e uma diferença importante nas operações entre serviços e manufatura é a presença do cliente no sistema de prestação de serviços (Portioli-Staudacher, 2009 apud Marchini et al., 2012).

A implantação do conceito lean no setor de serviços vem sendo aceita por empresas no Brasil e no mundo. Entretanto, exige a adaptação de alguns conceitos, como a noção do que são desperdícios. É mais fácil identificar os desperdícios quando são envolvidos matérias primas e processos de transformação física ou química. No setor de serviços, a maior parte das atividades diz respeito a geração de informações, o que torna mais difícil a identificação dos desperdícios, pois visualizar o processamento de algo intangível como a informação é bem mais complexo (Oliveira, 2012).

Desta forma, há exemplos de tipos de desperdícios que podem ser encontrados em processos de prestação de serviços, os quais, nem sempre, se enquadram na classificação dos sete tipos de desperdícios. Sob esta perspectiva, Lareau (2002), apud Oliveira (2012), designa alguns tipos de desperdícios relacionados ao ambiente corporativo, classificando-os em inúmeras categorias, conforme exposto a seguir: Alinhamento de objetivos: é a energia gasta por pessoas trabalhando com objetivos mal-entendidos e o esforço necessário para corrigir o problema e produzir o resultado esperado; Espera: é o recurso perdido enquanto pessoas esperam por informações, reuniões, assinaturas, o retorno de uma ligação e assim por diante; Controle: é a energia usada para controlar e monitorar e que não produz melhorias no desempenho; Variabilidade: são recursos utilizados para compensar ou corrigir resultados que variam do esperado; Alteração: é o esforço usado para mudar arbitrariamente um processo sem conhecer todas as consequências e os esforços seguintes para compensar as consequências inesperadas; Padronização: é a energia gasta por causa de um trabalho não ter sido feito da melhor forma possível por todos os responsáveis; Agenda: é a má utilização dos horários e da agenda; Fluxo irregular: recursos investidos em materiais ou informações que se acumulam entre as estações de trabalho e criam o desperdício de fluxo irregular; Checagens desnecessárias: é o esforço usado para inspeções e retrabalhos; Tradução: é o esforço requerido para alterar dados, formatos e relatórios entre passos de um processo ou seus responsáveis; Informação perdida: ocorre quando recursos são requeridos para reparar ou compensar as consequências da falta de informações chave; Falta de integração: é o esforço necessário para transferir informações (ou materiais) dentro de uma organização (departamento ou grupos) que não estão completamente integradas à cadeia de processos utilizados; Processos secundários: são os recursos despendidos em processos secundários que ainda não podem ser utilizados pelos passos seguintes do processo; Ativos subutilizados: são os equipamentos e prédios que não estão sendo usados de forma máxima; Transporte: todo transporte de materiais e informações, exceto aqueles utilizados para entregar produtos e serviços aos clientes; Falta de foco: ocorre toda vez que a energia e a atenção de um empregado não estão voltadas para os objetivos críticos da organização; Disciplina: ocorre sempre que 
existir uma falha no sistema de identificação acurada e reação rápida contra negligência, falta de responsabilidade e problemas relacionados à disciplina esperada dos empregados. É de fundamental importância a visão crítica ao analisar-se um processo de serviço visando a eliminação de desperdícios. Conforme citado anteriormente, esta análise é demasiada mais complexa, visto que envolve elementos intangíveis.

\section{METODOLOGIA}

O desenvolvimento da pesquisa foi realizado através do estudo de uma empresa júnior de consultoria, localizada na Universidade Federal de Viçosa (UFV), na cidade de Viçosa, Minas Gerais. O método utilizado neste estudo foi baseado no proposto por Rother e Shook (2003), com o objetivo de se obter a visão sistêmica do processo em questão e a identificação de possíveis pontos de melhoria. Os estudos na área do lean, geralmente, recomendam a seleção de uma família de produtos ou serviços para a realização da pesquisa. Neste trabalho, optouse por considerar o processo de serviços da empresa que gera um projeto de consultoria, com o objetivo de analisar as atividades e agentes envolvidos no processo de agregação de valor ao cliente na prestação do serviço. $\mathrm{O}$ próximo passo foi a coleta de informações, com o intuito de entender como o processo atual ocorre. Nesta etapa, buscou-se conhecer a organização, através da identificação das suas áreas de atuação no mercado e conhecimento da estrutura organizacional da empresa.

Mediante a realização de trabalhos anteriores, a empresa chegou à definição do processo de prestação de serviços atual, o qual é apresentado na Figura 1. Foram levantadas todas as atividades realizadas em cada fase desse processo, definindo-se os objetivos, atividades de cada diretoria e principais problemas encontrados. Para isso, realizou-se a análise de documentos da empresa, como Procedimentos Operacionais Padrão (POP's), Instruções de Trabalho (IT's) e Manuais; reuniões com os membros, assim como a observação direta de como o processo ocorre atualmente. Por ser tratar de serviços de consultoria, a coleta dos tempos foi realizada por meio de observação direta e de entrevistas com os membros em determinadas atividades. As métricas adotadas para facilitar a visualização de desperdícios foram: o Tempo de Ciclo (TC), considerado como o tempo que uma atividade é realmente completada em um processo; Tempo de Agregação de valor (TAV), definido como o tempo que efetivamente transforma-se o produto de uma maneira que o cliente está disposto a pagar e lead time, que neste estudo foi definido como o tempo total de prestação de um serviço de consultoria completo, desde o processo de vendas até a finalização do projeto.

Após o entendimento do processo, foram elaborados documentos parciais contendo as principais impressões do processo, os quais foram apresentados às diretorias envolvidas, com o objetivo de validar as informações levantadas. Além disso, foram compilados os principais problemas identificados em um primeiro momento, bem como os relatados pelos membros, através da elaboração de um diagnóstico organizacional. De posse de todas as informações necessárias, prosseguiu-se com a construção do mapa do fluxo de valor (VSM) atual, identificando-se o fluxo de informações, bem como o lead time associado. A confecção do VSM se deu com o auxílio do software Visio@.

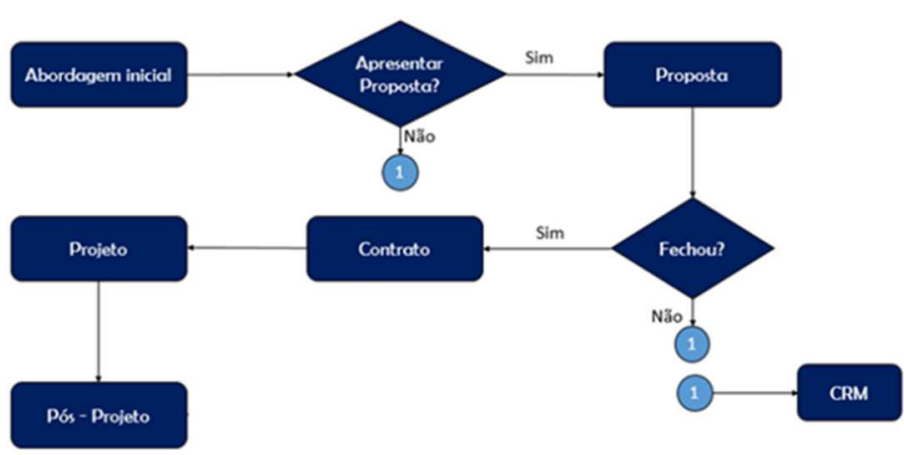

Figura 1 - Processo de serviço da Empresa Junior Soluções Consultoria.

Para a identificação dos desperdícios do processo, foram analisadas as métricas utilizadas no VSM e construídos diagramas de Ishikawa para a identificação das principais causas dos problemas encontrados. Desta forma, a proposição de melhorias no processo, visou atacar as causas dos desperdícios identificados. Por fim, foi construído o VSM futuro, considerando-se as melhorias propostas e a implantação dos princípios lean.

Ressalta-se que a implantação das melhorias propostas, depende de uma série de fatores que fogem do escopo deste trabalho. Desta forma, a etapa de definição e implantação de um plano de trabalho não foi realizada neste estudo, porém, as propostas de melhoria foram apresentadas à empresa, sendo a execução de sua responsabilidade. O fluxograma apresentado na Figura 2, resume as principais etapas que foram desenvolvidas.

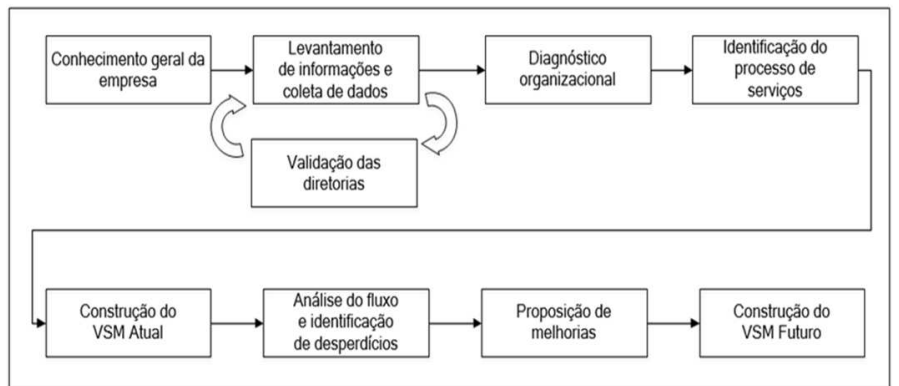

Figura 2 - Metodologia do estudo realizado.

\section{RESULTADOS}

O presente estudo analisou uma situação problema na Empresa Júnior de Engenharia de Produção e Mecânica, nomeada Soluções Consultoria, cuja sede localiza-se no campus Viçosa Universidade Federal de Viçosa (UFV), Minas Gerais. A Figura 3 apresenta o organograma da empresa, que atualmente é constituída por 25 alunos graduandos em Engenharia de Produção e Engenharia Mecânica da UFV.

Um dos objetivos atuais do Movimento Empresa Júnior (MEJ) é a realização de mais e melhores projetos, visando impactar de maneira positiva toda a sociedade. E para que isto ocorra, é necessário que haja o alinhamento das estratégias e processos das empresas juniores em torno de tal objetivo. Todavia, a empresa em questão apresentou alguns problemas relacionados aos dois eixos: dificuldades de atingimento das metas propostas e na qualidade dos projetos. Dentre os problemas relatados pelos membros, podem-se citar: baixa taxa de conversão de propostas em projetos; falta do gerenciamento adequado das informações dos clientes, ocasionando perda de dados e retrabalho para coletar novos dados e baixa fidelização 
de clientes. Ademais, as diretorias supracitadas atuam muitas vezes de maneira independente, não havendo coesão em torno do objetivo comum, que é tornar a experiência do cliente com a empresa a melhor possível.

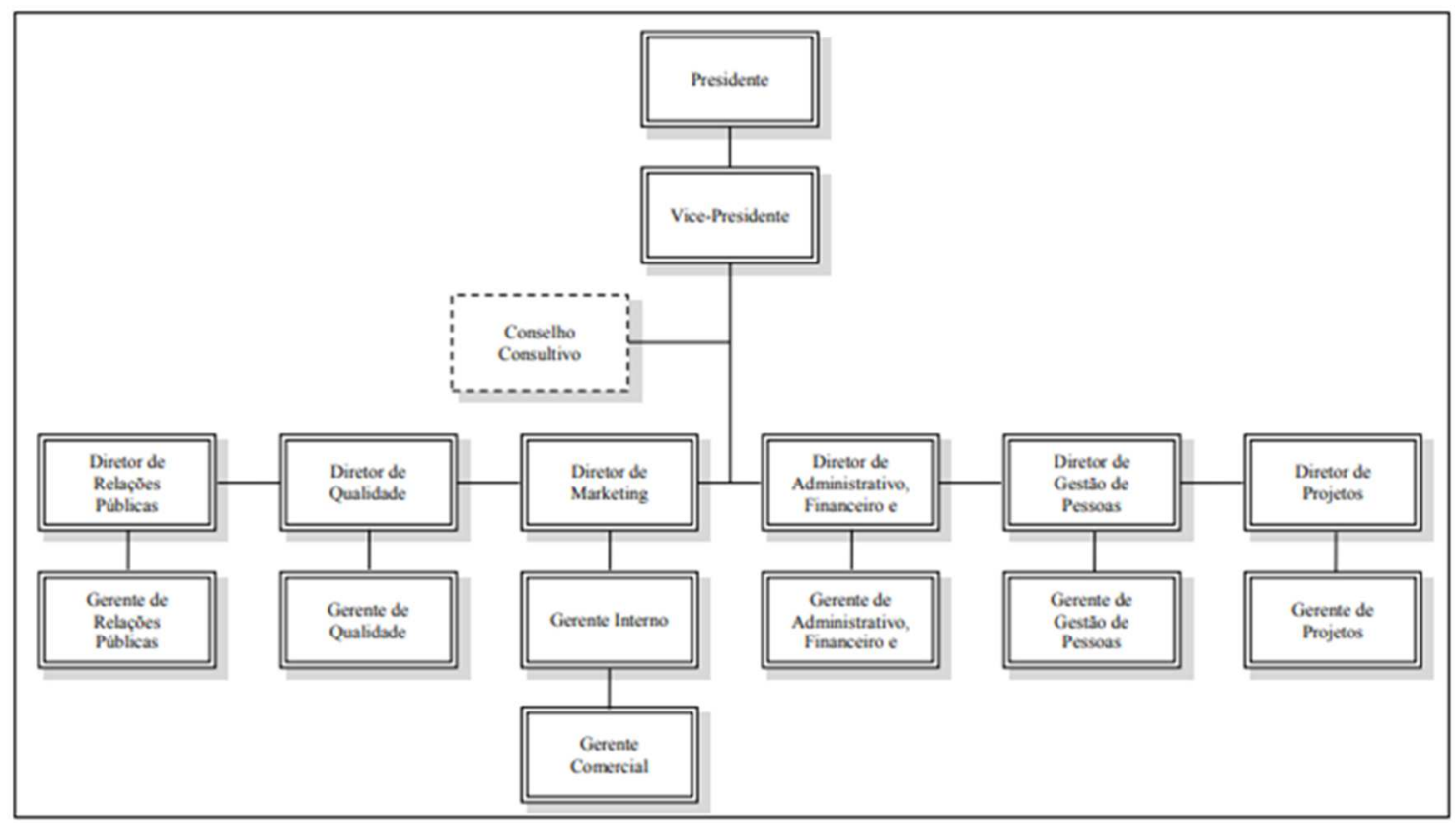

Figura 1 - Organograma da Empresa Júnior Soluções Consultoria.

Neste âmbito, pode-se observar que existem problemas em diversos pontos do processo de serviço, definido como uma série de passos pensados e desenhados para produzir o produto principal da empresa, que são os projetos de consultoria. Realizada a análise dos problemas citados, constatou-se que, de forma geral, nem todas as diretorias possuem a visão clara de seu papel neste processo, gerando outros problemas consequentes, conforme citado anteriormente. Ou seja, não existe uma visão global das atividades que geram valor para o cliente, o que cria um desalinhamento na empresa acerca das atividades a serem priorizadas, impactando diretamente o seu desempenho e a satisfação dos clientes. Considerou-se necessário o estudo do processo que gera valor aos clientes, possibilitando a identificação de pontos de melhoria com o objetivo de aprimorar seu desempenho e resolver os problemas supracitados.

\subsection{Identificação do Processo de serviço da Empresa Junior}

A identificação do processo de serviço da empresa, o qual é responsável pela prestação do serviço de consultoria, foi baseada na identificação inicial apresentada na Figura 1. O processo inicia-se com a abordagem inicial, através da qual é realizado o primeiro contato com um possível cliente. $\mathrm{O}$ objetivo principal é transmitir o valor dos serviços de consultoria e identificar, de forma detalhada, os problemas enfrentados pelo possível cliente, visando despertar o interesse para a continuação do contato com a empresa. Atualmente, esta etapa é realizada através de captação passiva, quando a demanda é identificada pelo próprio cliente, e pela captação ativa (a mais comum), que ocorre quando a empresa toma a iniciativa de fazer o contato com o cliente.

O processo de vendas inicia-se com o levantamento de suspects (potenciais clientes), pelo diretor de marketing e gerente interno de marketing, no caso da captação ativa. $\mathrm{Na}$ captação passiva, o próprio cliente entra em contato com a empresa solicitando um diagnóstico ou até mesmo um projeto específico. Em ambos os casos, o diretor de marketing atua como controle, compilando todos os clientes e dividindo-os entre os gerentes comerciais, semanalmente.

$\mathrm{Na}$ captação ativa, após a divisão das empresas, cada gerente comercial liga para os suspects buscando agendar um diagnóstico gratuito. Cada ligação dura em média 5 min, a qual tem o objetivo de explicar o que é uma empresa júnior, como trabalham e como funciona a reunião de diagnóstico. Por fim, caso o suspect apresente interesse, a avaliação é agendada. É importante ressaltar que nesta etapa, a grande maioria dos contatos não são convertidos em visitas, demandando um grande número de ligações. Já na captação passiva, os gerentes comerciais ligam para o suspect com o objetivo de entender melhor sua demanda e marcar a reunião para realização de um diagnóstico mais aprofundado.

O próximo passo é a visita comercial para a realização do diagnóstico. Nela, o gerente comercial conversa com o cliente com o intuito de conhecer melhor a empresa e identificar seus principais problemas, realizando um diagnóstico inicial. Esta visita demanda cerca de $1 \mathrm{~h}$, porém, é necessário considerar o tempo de preparação para a reunião e o transporte até a empresa-cliente que, em média, avaliou-se como $1 \mathrm{~h} 30 \mathrm{~min}$. Entretanto, este transporte foi considerado uma atividade que agrega valor, neste caso, visto que gera maior comodidade para o cliente, tendo-se que o mesmo não necessita locomover-se de sua empresa para realizar a avaliação.

A próxima etapa é a elaboração da proposta de projeto, caso o cliente tenha apresentado interesse, a qual é realizada por uma equipe formada por membros da empresa. Existem várias equipes de proposta, sendo que a alocação da equipe é feita a partir da sua disponibilidade, ou seja, são ocupadas as equipes que não estejam elaborando nenhuma outra proposta no momento. A equipe é responsável então pela elaboração do cronograma do projeto, precificação e carta proposta, utilizando os insumos fornecidos pelo gerente comercial, normalmente na forma de conversas e o documento utilizado no diagnóstico. 
Esta etapa requer um tempo total de $3 \mathrm{~h}$, em média, para a elaboração dos documentos que serão apresentados ao cliente. Entretanto, deve-se considerar que os membros precisam de tempo útil para agendar a reunião (visto que são estudantes e possuem outras atividades curriculares), além do tempo necessário para preparação e busca de informações. Assim, existe um tempo de espera de aproximadamente 5 dias entre a visita e esta etapa.

Com a proposta elaborada, esta deve ser validada pelo diretor de marketing, diretor de projetos e gerente interno. Nesta etapa, o gerente comercial envia por $e$-mail a proposta elaborada assim que o grupo de proposta finaliza a confecção dos documentos, não havendo assim tempo de espera entre estas etapas. Os responsáveis pela validação devem então revisar os documentos, a fim de evitar erros, aprimorar a proposta a ser apresentada, e dar o aval final para a apresentação ao cliente. A validação pode ser realizada em até $2 \mathrm{~h}$, porém normalmente leva-se até um dia para que a atividade seja realizada por todos os membros responsáveis e, caso necessário, sejam corrigidas falhas nos documentos.

O processo tem continuidade com a apresentação da proposta ao cliente. Nesta etapa, o gerente comercial apresenta o escopo do projeto ao cliente, objetivos e benefícios do projeto. Entre a validação da proposta e apresentação ao cliente, existe um tempo de espera (normalmente 3 dias), correspondente ao tempo necessário para o agendamento da reunião com o cliente. Esta reunião dura em média $1 \mathrm{~h}$, porém, assim como na vista comercial, existe o tempo de preparação e transporte até o local de, em média $1 \mathrm{~h}$ e 30 min. Posteriormente a apresentação do projeto, normalmente o cliente demanda um tempo para decidir pela aceitação ou não do projeto. Este tempo varia de cliente para cliente, mas normalmente tenta-se não deixar ultrapassar 1 semana. Caso o cliente contrate o projeto, o processo tem continuidade e as atividades demandas após o fechamento do projeto são executadas. Se o cliente não fecha o projeto, o processo é finalizado.

Após a sinalização de aceite do projeto pelo cliente, o gerente comercial deve solicitar à diretoria de Administrativo, Financeiro e Jurídico (AFJ) a confecção do contrato. É nesta etapa que é consolidada a venda para o cliente. Desta forma, a partir do momento que o gerente comercial envia os dados do contrato à $\mathrm{AFJ}$, um dos membros da diretoria elabora o contrato em um tempo médio de uma h, todavia, leva-se até um dia para terminá-lo, devido à necessidade de coletar assinaturas do professor orientador, presidente e gerente de projetos. Assim, após o contrato confeccionado, o gerente comercial apresenta o contrato ao cliente para que o mesmo seja assinado, em um tempo médio de $30 \mathrm{~min}$. Entretanto, o tempo entre a finalização da elaboração do contrato e a apresentação ao cliente, varia bastante, dependendo da disponibilidade do mesmo (foi considerado o tempo médio de 1 dia). Após assinado, o gerente comercial reenvia o contrato para a diretoria de AFJ.

Outras solicitações que o gerente comercial deve realizar após a sinalização de aceite do projeto, é a seleção de um auditor à diretoria de qualidade, e a solicitação de seleção de consultores (responsáveis pela execução do projeto) e membro apoio (membros alocados no projeto para auxiliar na realização de alguma atividade, caso necessário, e no esclarecimento de dúvidas) à diretoria de gestão de pessoas. Também deve-se solicitar a seleção do gerente de projetos à diretoria de projetos, e a elaboração de artes de divulgação do processo seletivo para consultores externos à diretoria de relações públicas. Além disso, um ponto importante a ser considerado é a averiguação de quem será o orientador ou responsável técnico pelo projeto.

A seleção de auditores e gerente de projetos é quase imediata, visto a necessidade de apenas dividir os projetos dentro das diretorias e alocar os membros que possuam maior disponibilidade no momento. Já o processo de seleção de consultores, normalmente possui um grande tempo de espera, posto que depende não só de membros da empresa, mas também alunos externos que serão entrevistados. Além disso, algumas vezes, os gerentes de gestão de pessoas precisam procurar alunos que já tenham cursado disciplinas específicas ou já possuam experiência para a realização do projeto. $\mathrm{O}$ processo inteiro dura aproximadamente 2 semanas.

Desta forma, é necessário divulgar a vaga nas redes sociais, aguardar que possíveis candidatos preencham o formulário de interesse, agendar entrevistas e, só então, realizar a seleção. As entrevistas duram, em média, uma h por pessoa e demais atividades do processo (análise de currículo e seleção final), 2 h. Assim, considerando-se a candidatura de 5 estudantes, o tempo médio para a realização da seleção de consultores é de $15 \mathrm{~h}$. Os membros apoio são membros internos da empresa que manifestam interesse em participar do projeto, respondendo ao e-mail enviado com este fim, pela diretoria de gestão de pessoas.

Após a seleção, o gerente de projetos deve agendar uma reunião com todos os consultores para a realização do planejamento do projeto. Nesta reunião são repassados os seguintes documentos: Cronograma Inicial, Gerenciamento de Riscos, Declaração de Escopo, Controle de Projetos, Lições Aprendidas. Além disso, são repassadas as principais informações que deverão orientar as atividades dos consultores durante o projeto. Esta reunião possui duração média de $2 \mathrm{~h}$.

Após a primeira reunião da equipe, os consultores devem entrar em contato com o cliente para agendar a primeira visita e, a partir desse ponto, são desenvolvidas pelos consultores as atividades inerentes ao projeto. A duração de cada projeto varia com o porte da empresa, tipo de serviço e a própria natureza do projeto. Durante a realização do projeto existem ainda atividades cíclicas, ou seja, que ocorrem periodicamente durante sua execução. Dentre as principais estão as reuniões de monitoramento, nas quais o gerente de projetos juntamente aos consultores deve analisar o desempenho do projeto em relação ao cronograma, custos e riscos do projeto. Cada reunião dura, em média, $1 \mathrm{~h}$. Ao decorrer de todo o projeto os consultores devem realizar reuniões com o cliente, conforme necessário, e preencher documentos específicos que serão utilizados nas reuniões de monitoramento. Devem ainda entregar ao cliente relatórios parciais do projeto com informações das atividades realizadas até o momento. Ao final do projeto, apresentam ao cliente o relatório final e os principais resultados obtidos. $\mathrm{O}$ tempo de duração de um projeto depende do tipo de projeto, complexidade do problema a ser resolvido, entre outros fatores. Assim, no mapa foi considerado o tempo médio para o desenvolvimento de um projeto atualmente, sendo de, aproximadamente, 62 dias. Entretanto, o tempo médio padrão de realização dos projetos é de 42 dias.

Como última etapa do processo de consultoria, o auditor deve realizar a auditoria, através da aplicação de um questionário, verificando quais foram as percepções do cliente em relação aos consultores e resultados obtidos. As auditorias 
normalmente ocorrem uma semana após a finalização do projeto e seu tempo de duração é de, aproximadamente, $1 \mathrm{~h}$.

\subsection{Mapa do fluxo de valor (VSM) atual}

Com base nas informações levantadas anteriormente foi construído o mapa do fluxo de valor atual da empresa (Figura 4), englobando as atividades-chave do processo e o fluxo de informações entre as diretorias. A análise do VSM possibilita a visão sistêmica das atividades-chave envolvidas no processo de prestação dos serviços de consultoria da empresa, bem como a identificação de desperdícios no processo e possíveis pontos de melhoria. De posse do mapa, observa-se um lead time total do processo de 100,5 dias, sendo o tempo de agregação de valor total de 43,26 dias. Assim, pode-se interpretar essas informações dizendo-se que o tempo médio dispendido com um cliente que contrata um serviço de consultoria é de 100,5 dias, sendo que as atividades responsáveis pelo valor enxergado pelo mesmo são de 43,26 dias.

Outra conclusão que se pode chegar, através das impressões obtidas junto aos membros da empresa, é que a maior parte das atividades, de fato, podem ser classificadas como atividades necessárias e que agregam valor ao processo. Entretanto, a configuração atual do fluxo de informações gera perdas no processo que impacta no tempo de outras atividades. Uma observação importante a ser ponderada é que foi considerado o tempo médio para o tempo de ciclo de algumas etapas do processo, visto que o processo de serviço de consultoria é amplamente dependente do cliente, logo, o tempo de realização de algumas atividades depende do mesmo. Assim, o tempo de espera entre o telefonema para o suspect e a realização da visita é variável, porém, foi considerado 4 dias, em média, visto que nem sempre o cliente pode agendar a reunião para o mesmo dia da ligação, mas normalmente prefere marcála para a mesma semana. $\mathrm{O}$ mesmo se aplica para a apresentação da proposta ao cliente.

Além disso, a etapa de solicitações tem um tempo médio de $30 \mathrm{~min}$, posto que são feitas online. Entretanto, devido ao número de solicitações feitas separadamente, muitas vezes, o gerente comercial não se recorda de realizar todas, executandoas tardiamente ou mesmo não executando-as. Para as atividades de elaboração do documento de contrato do projeto; seleção de auditor; elaboração da arte; realização de recrutamento e seleção de consultores, membro apoio e avaliador interno, foi representado o maior tempo de ciclo (seleção de consultores), visto que são atividades que podem acontecer paralelamente.

Dois pontos críticos principais podem ser identificados, sendo eles o processo de seleção de consultores que atualmente possui tempo de ciclo de 14 dias, porém apenas $15 \mathrm{~h}$ são de atividades que agregam valor (Figura 4). Outro ponto identificado é o atraso no tempo médio de realização dos projetos, sendo o previsto de 42 dias e o real de 62 dias, representando um atraso de 20 dias, em média. É importante que se esclareça que a maioria das atividades estão sendo analisadas baseando-se em um tempo médio, visto que os serviços de consultoria dependem altamente da interação com o cliente, sendo esta uma variável que introduz certo nível de imprevisibilidade em relação ao tempo de execução de algumas atividades.

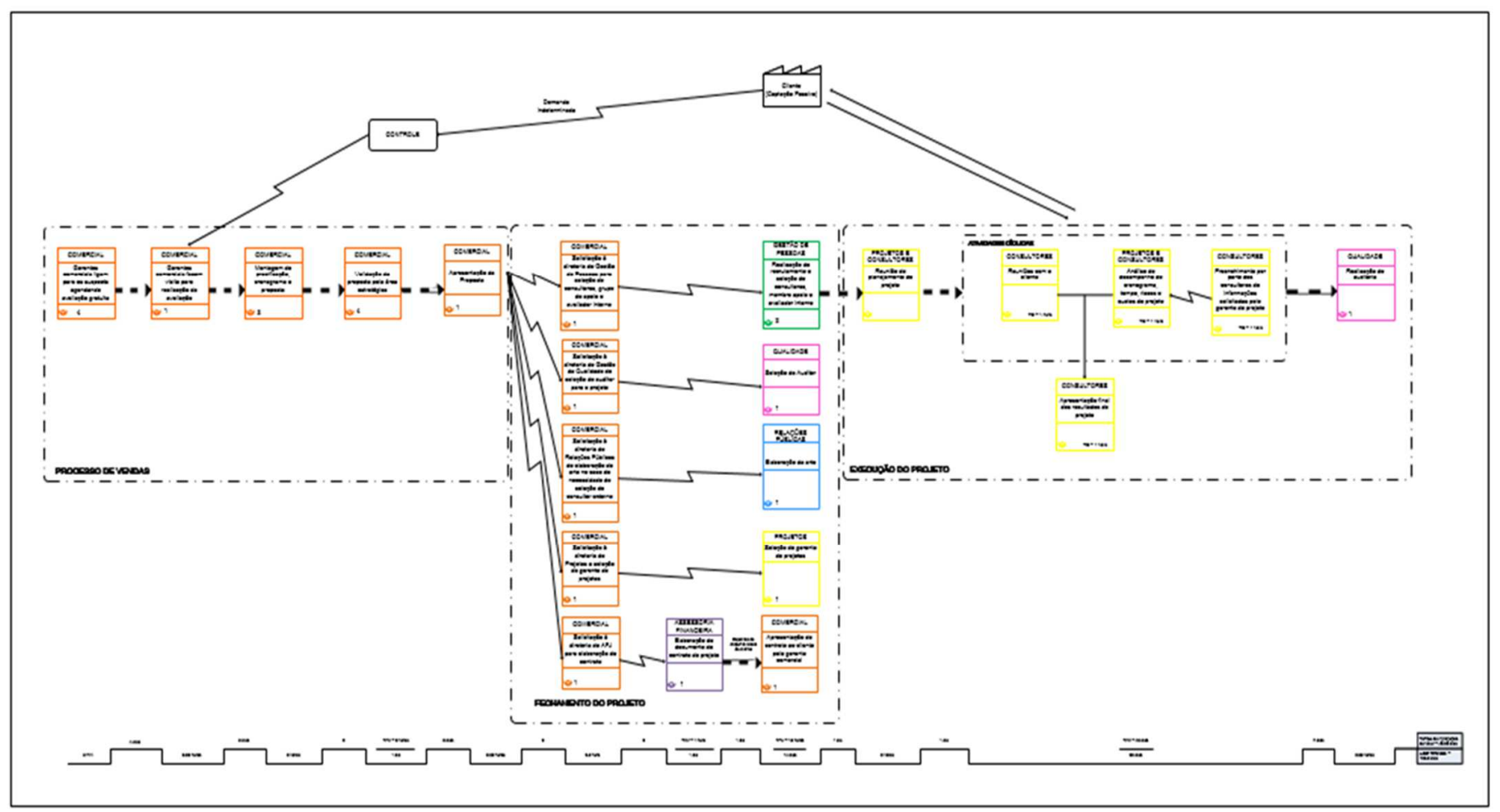

Figura 4 - Mapa de fluxo de valor atual da Empresa Júnior.

\subsection{Identificação dos desperdícios}

Com base nos sete tipos de desperdícios do lean thinking, são apresentados os desperdícios identificados no processo:

Perda por superprodução: muitas vezes são estabelecidas muitas atividades a serem cumpridas sem que se dê o devido foco às atividades prioritárias;

Perda por transporte: durante a fase de fechamento do projeto, o gerente comercial necessita realizar, de forma separada, muitas solicitações a diversas diretorias, o que gera um transporte desnecessário de informações. Embora não se 
observe diretamente no mapa, este fluxo impacta no tempo de realização das atividades subsequentes;

Perda por fabricação de produtos defeituosos: o não cumprimento dos prazos acordados, conforme cronograma, pode ser considerado um tipo de defeito, o que resulta em atrasos no tempo de realização dos projetos; Documentos do projeto entregues ao cliente com erros de formatação: É um fator que influencia na qualidade do projeto e está relacionado diretamente a um dos pilares do lean de agregação de valor ao cliente. Além disso, defeitos nos documentos entregues ao cliente podem resultar em atrasos no cronograma, visto que geram retrabalho;

Perda por espera: espera para começar o projeto até a seleção dos consultores: $O$ atraso na seleção dos consultores, atrasa, consequentemente, o início de execução do projeto; Espera até o cliente decidir se fecha ou não projeto: durante a negociação, o cliente pode demandar um tempo para decidir pela contratação ou não do projeto. É considerado espera, pois aloca tempo dos gerentes comerciais, que devem manter contato constante com esses clientes. Devido à especificidade do setor de serviços, alguns desperdícios não se enquadram na classificação anterior. Assim, surgem outros tipos de classificação, conforme exposto no referencial teórico. Desta forma, foram identificados outros desperdícios baseando-se nessa concepção:

Falta de integração: conforme exposto anteriormente, nem todas as diretorias trabalham de forma integrada em torno do mesmo objetivo. Assim, existe um esforço adicional necessário para transferir informações dentro da empresa;

Falta de alinhamento de objetivos: energia é gasta por pessoas trabalhando com objetivos mal-entendidos, existindo ainda o esforço para corrigir o problema e atingir o esperado;

Fluxo irregular (fluxo de informações inadequado na etapa de fechamento do projeto): o grande fluxo de informações que existe entre diversas diretorias no período de fechamento do projeto, conforme ocorre atualmente, não é o mais adequado. Durante esta etapa do processo é comum a existência de gaps de informações, o que prejudica as demais etapas do processo. Como não ocorre de maneira eficaz, normalmente gera atrasos nas demais atividades, como na seleção de consultores;

Informação perdida (falta de registro adequado de informações do cliente): atualmente, durante o processo de vendas, não existe o armazenamento correto de informações dos clientes. Desta forma, quando é necessário levantar alguma informação, como qual projeto foi oferecido na época da negociação, número de funcionários da empresa, etc.; é necessário recorrer a várias pessoas, com o intuito de descobrir quem fez o contato com tal cliente, e se possui as informações procuradas. Além disso, a falta deste registro inviabiliza o direcionamento do cliente no Funil de Vendas, tornando o processo de vendas menos eficaz, prejudicando a taxa de conversão de propostas em projetos (uma das etapas do Funil de Vendas). Embora a empresa utilize um software de CRM, nem todos os membros da diretoria comercial sabem como utilizar todos os recursos da ferramenta e, ao mesmo tempo, na maioria das vezes, não sabem ao certo quais informações devem inserir;

Elaboração não assertiva de cronogramas: a elaboração não assertiva dos cronogramas é um dos principais pontos responsáveis pelo atraso na conclusão dos projetos, em relação ao cronograma inicial planejado. Isto ocorre, na maioria das vezes, pela falta de experiência dos membros que estão elaborando o cronograma na área do projeto, ou pela perda de informações no processo de transferência dos dados do gerente comercial para o grupo de proposta;

Falta de preparação dos consultores para a realização dos projetos: anteriormente à realização do projeto, não existe nenhum tipo de capacitação técnica específica para o desenvolvimento das atividades. Desta forma, por um lado, alguns consultores acabam se sentindo sobrecarregados durante a realização dos projetos por terem que desenvolver as tarefas designadas no cronograma e estudar assuntos mais técnicos relacionados ao projeto, ao mesmo tempo. Por outro, existe o risco de a falta de preparação dos consultores resultar em projetos que não atendam às expectativas do cliente no quesito qualidade.

Os desperdícios apresentados podem ser classificados como causas de dois grandes problemas identificados no mapa de fluxo de valor: o atraso no recrutamento e seleção de consultores e o atraso e/ou falta de qualidade dos projetos. Baseado nisto, duas grandes possíveis áreas de melhoria foram identificadas: recrutamento/seleção de consultores e realização do projeto.

O recrutamento e seleção de consultores é um ponto crítico no processo, visto que o atraso na seleção de consultores, atrasa consequentemente, o início do projeto. Atualmente, esta atividade dura cerca de 14 dias, porém, o tempo de agregação de valor é baixo, sendo de aproximadamente $15 \mathrm{~h}$. O diagrama de Ishikawa (Figura 5), apresenta as possíveis causas, de acordo com a observação direta do processo, para o atraso desta atividade.

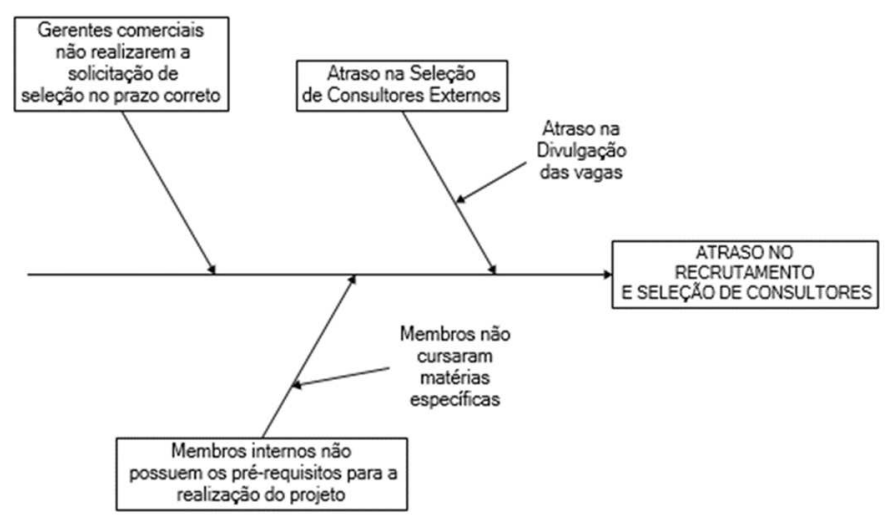

\section{Figura 5 - Diagrama de Ishikawa para o atraso no recrutamento e seleção de consultores.}

O tempo de realização dos projetos de consultoria varia conforme o tipo de empresa a ser atendida e o problema do cliente a ser resolvido. Atualmente, de forma geral, o tempo médio real de realização dos projetos é de 62 dias, enquanto o planejado é de cerca de 42 dias. Além disso, nem todos os projetos são realizados com a qualidade desejada, não atendendo, muitas vezes, as expectativas dos clientes. A Figura 6 ilustra as possíveis causas, de acordo com a observação direta do processo, para os problemas identificados nesta etapa. 


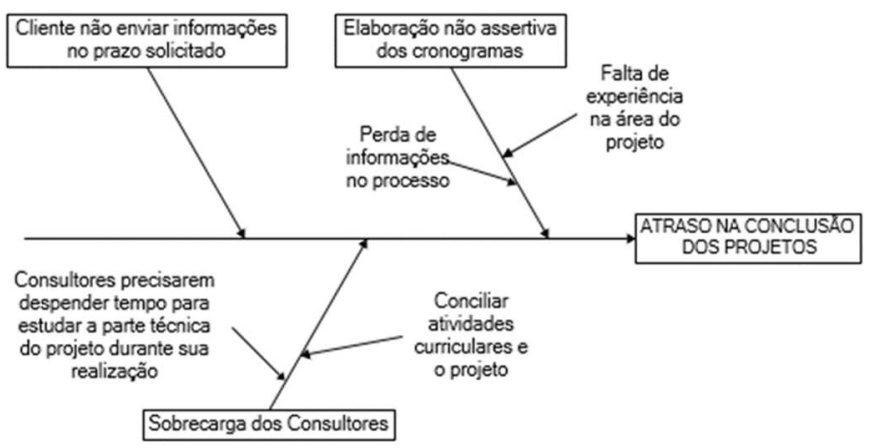

Figura. 6 - Diagrama de Ishikawa para atraso na conclusão dos projetos.

\subsection{Proposição de melhorias}

Deve-se ressaltar que durante o período de desenvolvimento deste trabalho houveram mudanças na estrutura organizacional, propostas e implementadas pelos próprios membros da empresa, visando justamente eliminar alguns dos desperdícios citados anteriormente, principalmente os relacionados à falta de integração e alinhamento de objetivos. Desta forma, mudanças no organograma (sugerida pela área estratégica) foram efetuadas, com o objetivo de tornar o fluxo de informações mais contínuo e proporcionar melhor integração entre as diretorias. O novo organograma da empresa é apresentado na Figura 7.

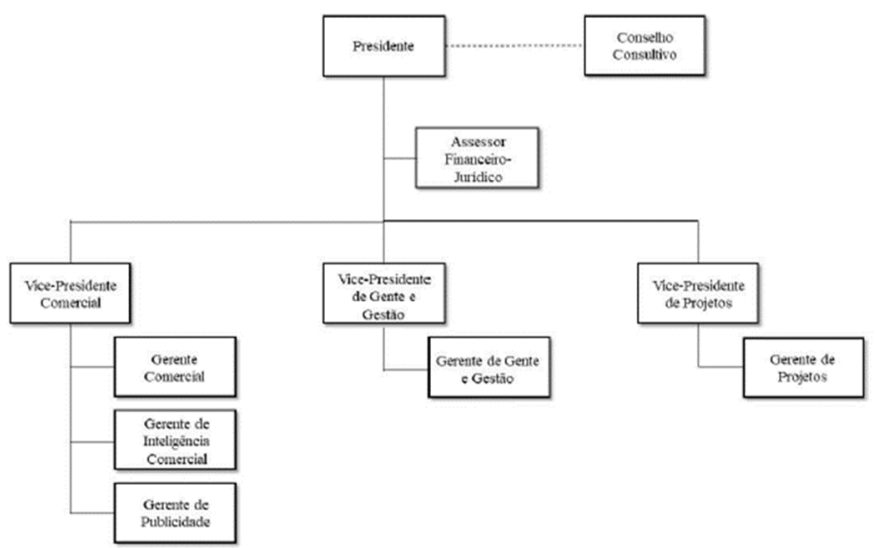

Figura 7 - Novo organograma da empresa (mudança proposta pelos próprios membros).

É importante lembrar que, de forma geral, as atividades de cada cargo não sofreram alterações, as principais mudanças foram em relação ao fluxo das atividades, apresentando-se como um organograma bem mais "enxuto" em relação ao anterior. A seguir são listadas as principais sugestões de melhoria para a eliminação dos desperdícios e agregação de valor ao processo.

Centralização de informações: recentemente a empresa adquiriu uma nova ferramenta que irá auxiliar na centralização de informações, sendo que através desta base, todos terão acesso rápido à dados que necessitem. Desta forma, para a eliminação do grande número de solicitações a serem realizadas pelo gerente comercial após o fechamento do projeto, sugere-se a criação de um local específico dentro desta ferramenta, no qual os gerentes comerciais irão registrar todas as informações do projeto e as solicitações necessárias. Assim, basta que ele avise, por exemplo, no grupo do aplicativo whatsapp da empresa que os dados já se encontram disponíveis. Logo, elimina-se o grande número de e-mails ou mensagens de whatsapp a serem enviadas separadamente, o que reduz o tempo despendido com tal atividade, além de minimizar a perda de informações importantes durante este processo.

\section{$\underline{\text { Registro adequado de informações de clientes no CRM }}$}

Para resolver o problema de falta de registro adequado de informações dos clientes, foi criado um documento explicativo indicando os recursos do software Ploomes $@$, CRM utilizado pela empresa, e como deve ser utilizado. Além disso, foi criado um checklist (Figura 8) com todas as informações que o gerente comercial deve inserir no software, após a realização da visita.

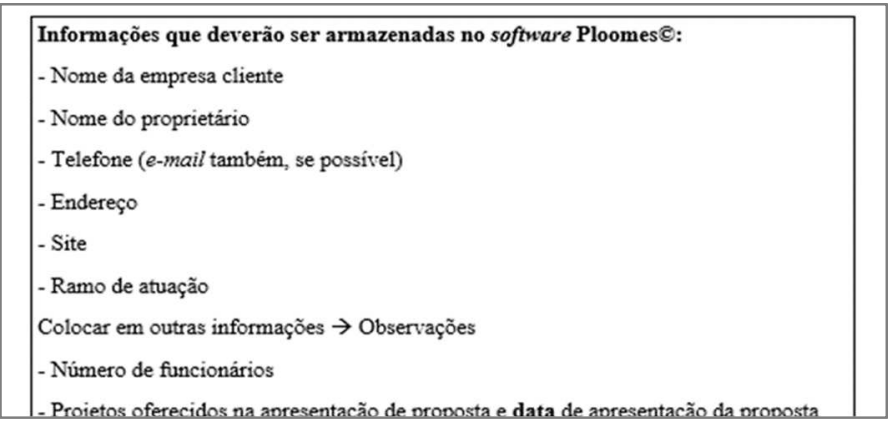

\section{Figura 8 - Excerto do checklist: informações a serem} inseridas no CRM.

Elaboração de cronogramas: para minimizar a perda de informações durante a transferência do gerente comercial para a equipe de proposta, um dos membros da empresa sugeriu a criação de um checklist contendo todas as informações necessárias a serem repassadas. O checklist elaborado é apresentado na Figura 9. Sugere-se ainda que o mesmo checklist seja utilizado no e-mail enviado à área estratégica para validação dos cronogramas.

\section{CHECKLIST DE INFORMAÇÕES}

- Número de funcionários,

- Setor de atuação,

- Localização da empresa (Importante para a estimativa de custos na precificação),

- Linhas de produtos e/ou serviços (Especificar número e quais são),

- Nivel de complexidade dos processos da empresa,

- Disponibilidade de tempo do cliente para reuniões e envio de informações (normalmente - cliente se encontra no estabelecimento durante todo o expediente ou apenas em

Figura 9 - Excerto do checklist: informações a serem repassadas pelos gerentes comerciais.

No que tange ao outro fator que contribui para a elaboração de cronogramas não assertivos, ou seja, a falta de experiência dos membros na área do projeto, recomenda-se a elaboração de cronogramas com os tempos reais gastos em cada atividade. Desta forma, torna-se possível a comparação entre o cronograma planejado e o cronograma real. Outras informações importantes que deverão estar presentes nos cronogramas reais, são informações básicas, como setor de atuação da empresa e número de funcionários, visto que são fatores que influenciam na duração e tipo de atividades presentes no cronograma. Desta forma, presume-se que os cronogramas elaborados a partir destes cronogramas base, passarão a ser mais próximos do real.

Banco de dados de possíveis consultores: um dos motivos de atraso no processo de recrutamento de consultores para os projetos, é a seleção de consultores externos. Desta forma, sugere-se a criação de um banco de dados no qual seja registrado informações básicas de pessoas que tenham interesse em realizar um projeto de consultoria da empresa. Pode-se criar 
um questionário online, divulgá-lo nas redes sociais e solicitar que as pessoas interessadas o preencham. Um modelo de formulário é apresentado na Figura 10.

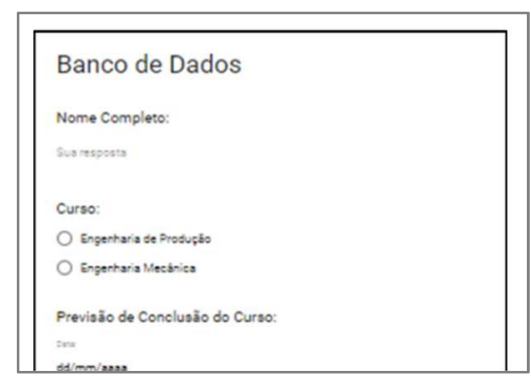

\section{Figura 10 - Excerto do formulário: banco de dados de possíveis consultores.}

Assim, sempre que necessário, pode-se recorrer diretamente a este banco de dados, eliminando o período de divulgação das vagas e de pré-análise do perfil dos candidatos. Desta forma, pressupõe-se uma diminuição considerável no tempo solicitado no processo de recrutamento e seleção de consultores.

Fidelização de clientes: a retenção de clientes é um dos fatores fundamentais para o sucesso de um negócio. Segundo Kotler (1999), conquistar um novo cliente custa de 5 a 7 vezes mais que manter um atual. Além disso, ao manter seus clientes satisfeitos, a empresa agregará mais valor ao negócio, criando autoridade para sua marca e relevância no mercado, além de possuir menos custos.

Desta forma, pode-se enxergar a falta de fidelização de clientes como um desperdício, uma vez que se torna necessário maior investimento de tempo e dinheiro no processo de vendas. Por outro lado, este é um indicativo de que a empresa não tem conseguido entregar o valor prometido aos seus clientes. Podese inferir que o principal fator que faz um cliente da empresa em questão tornar-se fidelizado é a capacidade de resolução de seus problemas, por meio dos projetos oferecidos. Entretanto, conforme exposto anteriormente, existem alguns desperdícios no processo que contribuem para a não realização adequada de todos os projetos, como a falta de preparação adequada dos consultores para a realização dos projetos e a realização de entregas com erros ou que não correspondam às expectativas do cliente. Cada etapa, cada interação com o cliente e cada entrega, é crucial para determinar seu nível de satisfação final em relação ao serviço prestado. Assim, a fidelização de clientes é responsabilidade de toda a empresa e não de uma diretoria específica. Neste âmbito, propõe-se a adoção de um modelo de fidelização de clientes, o qual envolveria toda a empresa, gerando o engajamento de todos os membros na geração do objetivo final de satisfazer às necessidades dos clientes e fidelizá-los. O propósito deste processo (Figura 11) é a eliminação de alguns dos desperdícios apresentados e a agregação de valor ao processo de serviço da empresa. A seguir são descritas as etapas do modelo de fidelização de clientes:

(1) Alinhamento cliente e soluções: esta etapa tem por objetivo levantar informações mais detalhadas acerca do cliente e verificar se ele efetivamente espera do projeto o que foi apresentado na proposta, para que não haja um desalinhamento de expectativas em relação ao projeto. Fases:

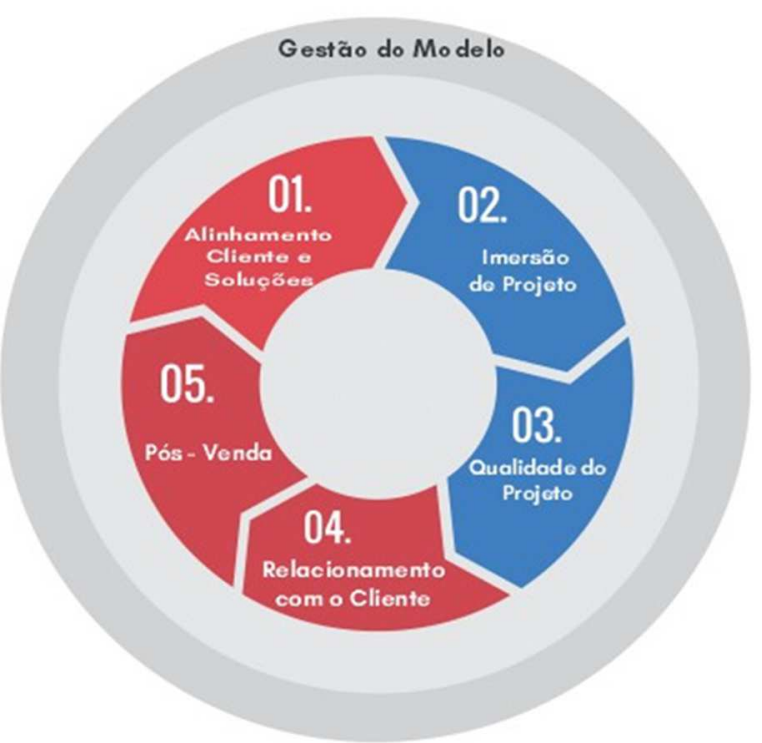

Figura 11 - Modelo de fidelização de clientes Soluções Consultoria.

- Questionário de construção da Buyer Persona: deve-se aplicar um questionário ao cliente para levantar características e comportamentos, os quais servirão como insumo para saber como lidar com o cliente ao longo do projeto; quais os meios de comunicação que prefere utilizar, se prefere uma comunicação mais formal ou informal, nível de instrução, dentre outras. Tais informações deverão ser repassadas para a equipe do projeto, com o intuito de direcionar o contato com o cliente.

- Apresentação de resultados de projetos anteriores: devese apresentar documentos, planilhas, fluxogramas, de projetos semelhantes realizados anteriormente, com o intuito de identificar o que o cliente espera e o que não espera do projeto, verificando se compreendeu bem o escopo e se este supre suas expectativas.

(2) Imersão de projeto: esta etapa tem por objetivo garantir a capacitação dos consultores para a realização do projeto, oferecendo o apoio necessário para que se sintam mais seguros para a realização das atividades, além de aumentar a possibilidade de que estas sejam melhores executadas. Ademais, esta etapa visa reduzir o desperdício identificado na etapa de realização dos projetos, relacionado ao tempo despendido durante a execução das atividades para o estudo simultâneo do tema do projeto. Fases:

- Instituir uma semana de estudos dos projetos, anterior à data inicial das atividades, na qual os consultores deverão estudar e discutir os temas e ferramentas relacionados ao projeto. Além disso, pode-se realizar uma reunião (presencial ou online - via skype $e^{\odot}$ ou hangouts $^{\odot}$ ) envolvendo a equipe do projeto e membros ou ex-membros da empresa que tenham realizado algum projeto na área. O objetivo é proporcionar a troca de experiências, sugestões de boas práticas para a realização do projeto e principais dificuldades encontradas. É recomendada ainda, a leitura de Cases e Lições Aprendidas de projetos anteriores realizados na mesma área. Tais observações deverão ser documentadas para possibilitar a consulta por outros membros que venham 
a realizar um projeto na área, futuramente;

- Disponibilizar para os consultores material de apoio que deverá ser estudado. Esta biblioteca seria construída progressivamente e armazenada na nuvem eletrônica da empresa (atualmente existe apenas para alguns projetos); deve-se então, caso necessário, elaborar um plano de ação para contornar as principais dificuldades identificadas durante a "Troca de Experiências" e na fase de estudos, antecipando-se problemas e atacando-os antes mesmo que ocorram. Considerar o tempo despendido neste processo no momento de elaboração do cronograma.

(3) Qualidade do projeto: esta etapa visa garantir a qualidade das entregas e que estas atendam às expectativas do cliente, reduzindo ainda os defeitos e retrabalhos dos documentos elaborados. Fases:

- Acompanhamento do cliente: para todos os projetos, realizar entregas parciais ao final de cada pacote de trabalho, possibilitando a oportunidade de validação pelo cliente do que está sendo realizado, além de recolhimento de suas opiniões e sugestões; realizar auditorias periodicamente: Determinar a periodicidade de acordo com o projeto;

- Avaliação da Equipe: realizar avaliações internas da equipe do projeto periodicamente, traçando planos de ação para a resolução de possíveis problemas;

- Revisão das entregas do projeto: instituir uma equipe para revisar os documentos finais do projeto elaborados pelos consultores, que deverão ser entregues aos clientes (manuais, planilhas), evitando que tais documentos sejam entregues com erros.

(4) Relacionamento com o cliente: esta etapa tem por objetivo estreitar o relacionamento entre as partes, criando uma conexão mais pessoal entre a empresa e o cliente, o que contribui para a agregação de valor aos serviços prestados. Fases:

- Entrega de um brinde com a logomarca da empresa no dia da apresentação final do projeto;

- Envio de mensagens por whatsapp(C em datas comemorativas (Natal, Ano Novo, Dia das Mães/Pais), ao menos durante o período de realização do projeto, demonstrando assim, cuidado com o cliente e pessoalidade.

(5) Pós-venda: objetiva-se manter o contato com o cliente mesmo após a realização do projeto, contribuindo para a agregação de valor ao cliente. Fases:

- Reunião pós-venda: após determinado tempo da realização do projeto, telefonar para o cliente marcando uma reunião, na qual deverá ser perguntado como está a empresa, perspectivas do cliente para os próximos meses, se o projeto realizado está gerando resultados (caso o cliente apresente alguma reclamação, registrar e analisar como poderá ser resolvida). Esta reunião é ainda, uma oportunidade de identificação da necessidade de um novo projeto;

- Coleta de indicadores: efetuar a coleta de indicadores de desempenho do projeto, com o intuito de comparar com o indicador de desempenho inicial, demonstrando a efetividade do projeto;

- Marketing one to one: abordagem mais humanizada e personalizada, pautada no conhecimento do cliente.

A partir das informações coletadas em todas as etapas anteriores acerca do cliente, é possível definir outras estratégias de fidelização, de forma individual e personalizada, sendo que esta abordagem deverá ser aplicada apenas quando todas as demais etapas estiverem bem estruturadas e funcionando.

Gestão do Modelo: a fidelização é consequência do envolvimento, engajamento e foco de toda a empresa no objetivo principal de criar soluções inteligentes para os clientes, satisfazendo suas necessidades. Entretanto, por ser um modelo que envolve diversas atividades e a participação de toda a empresa, é necessário que haja um gerenciamento deste processo e que este seja o mais transparente e visível possível para todos. Neste sentido, sugere-se o estabelecimento de indicadores a serem medidos após determinado tempo da utilização do modelo (como comparação do nível de satisfação dos clientes antes e depois da adoção do modelo, número de clientes que voltaram a entrar em contato com a empresa, etc.). Isto visando-se mensurar sua efetividade e traçar planos de ação para sua melhoria.

Mapa de fluxo de valor (VSM) futuro: o VSM futuro foi construído levando-se em consideração as sugestões de melhoria propostas para os dois pontos críticos identificados: processo de seleção de consultores e execução do projeto. Com a implementação das sugestões, espera-se que o tempo para a realização da seleção dos consultores reduza consideravelmente, visto que com o banco de dados o tempo de espera de divulgação das vagas e manifestação de interesse seriam eliminados. Além disso, a análise curricular seria facilitada, tendo-se todos os dados disponíveis previamente. Posto isso, o tempo total para a realização desta atividade, considerando-se a candidatura de cinco pessoas, seria de $10 \mathrm{~h}$, sendo $1 \mathrm{~h}$ de entrevistas por candidato e $1 \mathrm{~h}$ para demais atividades do processo (análise de currículo e seleção final) por candidato. Em relação à execução dos projetos, com todas as sugestões de melhoria propostas, espera-se que os atrasos no projeto, devido aos variados fatores expostos anteriormente, sejam eliminados e o tempo médio de execução seja reestabelecido, ou seja, 42 dias. Além disso, as sugestões visam ainda aumentar o valor agregado ao cliente, atendendo às suas expectativas. Outro ponto considerado no mapa futuro foi a diminuição de alguns fluxos de informação, tornando o processo mais simples, objetivo, eficaz e diminuindo as chances de perda de informações importantes. Entretanto, deve-se ressaltar que não foi eliminada nenhuma atividade do processo, visto que todas são necessárias, agregando ou não valor ao processo.

Logo, diante das informações apresentadas, o lead time total do processo passou de 105,5 dias para 66,93 dias, representando menor dispêndio de recursos com o cliente durante a prestação de serviços, porém sem diminuição da qualidade, visto que as diversas proposições de mudanças tiveram como foco o cliente e a agregação de valor ao mesmo. O VSM futuro com todas estas considerações é apresentado na Figura 12. 


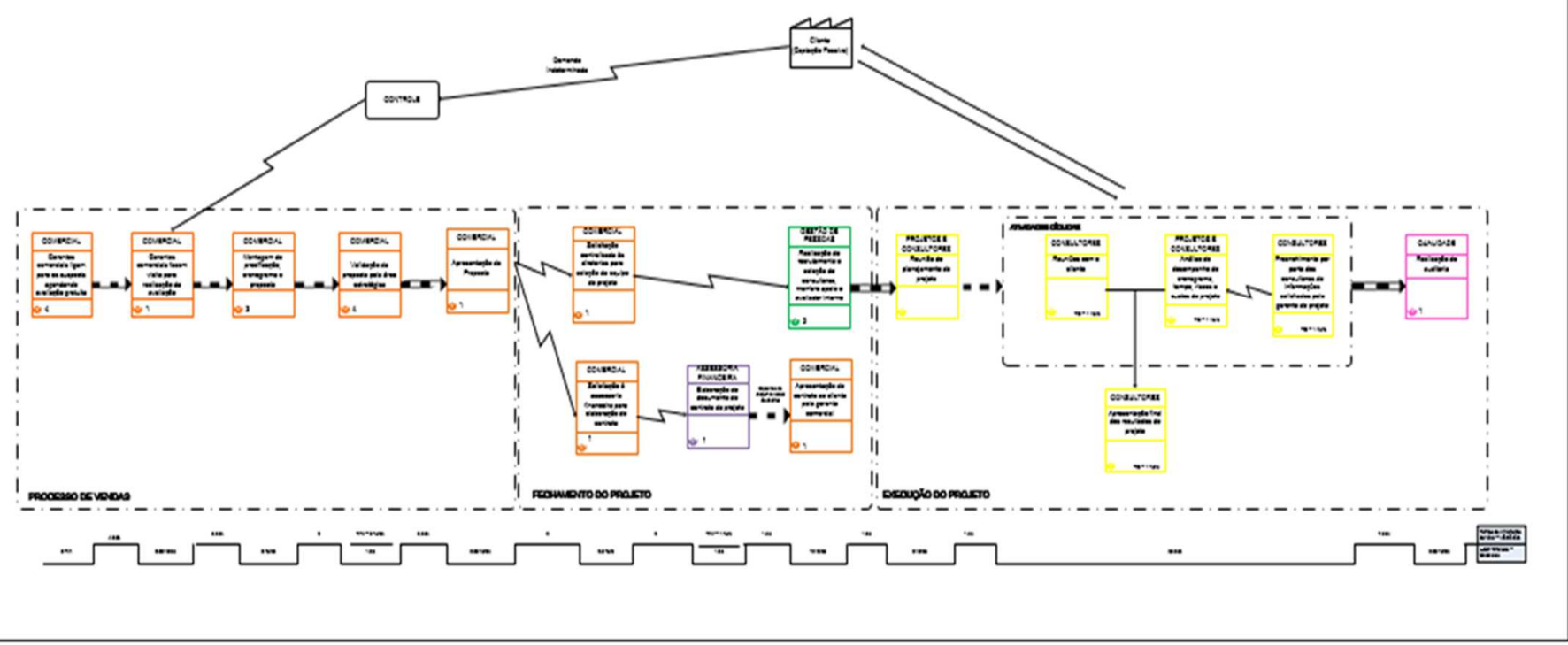

Figura 12 - Mapa do Fluxo de Valor Futuro.

\section{CONCLUSÕES}

O presente trabalho aplicou alguns conceitos relacionados ao lean service em uma empresa júnior de consultoria com o intuito de auxiliar na melhoria de processos. Foram elaborados mapas do fluxo de valor (VSM) do estado atual e do estado futuro. Com isto conclui-se que:

- As propostas de melhoria sugeridas indicam uma configuração do processo com a diminuição do lead time de prestação de serviços de 105,5 dias para 66,93 dias. Como principais restrições pode-se citar as peculiaridades inerentes ao setor de serviços, como a intangibilidade dos fluxos, tornando mais subjetiva sua análise:

- Os serviços de consultoria, especificamente, possuem grande envolvimento dos clientes durante todo o processo, o que faz com que muitas atividades possua o tempo de execução bastante variável, dificultando sua análise. Pode-se citar, por exemplo, as etapas de agendamento de visitas ao cliente, as quais dependem da disponibilidade do mesmo, não sendo o tempo de ciclo passível de padronização;

- A aplicação dos conceitos lean em uma organização prestadora de serviços representa uma contribuição ao conhecimento, posto que é uma metodologia ainda pouco difundida no setor. Tal modelo de gestão, permite significativas contribuições para análise dos processos de uma empresa, visando-se melhorias a curto e longo prazo.

\section{REFERÊNCIAS}

BORDALO, S. N.; FERZIGER, J. H.; KLINE, S. J. The Development of Zonal Models for Turbulence, In: Proceedings of the 10th Brazilian Congress of Materials
Engineering. 1989, Rio de Janeiro: ABM, v.2, p. 41-44.

BELLEI, L. M. Aplicação do Mapeamento do Fluxo de Valor em uma Indústria Gráfica. Universidade Federal de Juiz de Fora, 2010.

BULHÕES, I. R. Diretrizes para implementação de fluxo contínuo na construção civil: uma abordagem baseada na Mentalidade Enxuta. Tese (Doutorado em Engenharia Civil) - Unicamp, SP, 2009.

CARDOSO, G. O. A.; SOUZA, J. P. E.; ALVES, J. M. Lean Office aplicado em um Processo de Auditoria de Certificação de Sistema de Gestão da Qualidade Aeroespacial, 2012.

COLECCHIA, A.; GUELLEC, D.; PILAT, D.; SCHREYER, P.; WYCKOFF, A. A New Economy: The Changing Role of Innovation and Information Technology in Growth. OECD, Paris, France, 2002.

CORRÊA, H. L.; CAON, M. Gestão de Serviços: Lucratividade por Meio de Operações e de Satisfação dos Clientes. São Paulo: Atlas, 2002.

DATA SEBRAE. Disponível em:< http://datasebrae.com.br/pib/> Acesso em: 03 de junho de 2018.

FITZSIMMONS, J. A.; FITZSIMMONS, M. Administração de serviços: operações, estratégia e tecnologia de informação. Porto Alegre: Bookman, 4. ed., 2005.

FONSECA, C. M. F. A. Aplicação dos princípios Lean ao sistema de prestação de serviços de assistência em viagem automóvel. Instituto Universitário de Lisboa, 2012.

FORTES, C. S. Aplicabilidade de Lean Service na melhoria de serviços de tecnologia da informação (TI). Universidade Federal do Rio Grande do Sul, 2010. 
KOTLER, P.; ARMSTRONG, G. Princípios de Marketing. São Paulo: Atlas, 1999.

KUBR, M. Consultoria - um guia para a profissão. Rio de Janeiro: Guanabara Koogan, 1986.

MOSER, J. L. M. Consultoria - O que é e para que serve? 2009. Disponível em: <http://www.administradores.com.br/artigos/negocios/c onsultoria-o-que-e-e-para-que-serve/40610/> Acesso em: 29 de maio de 2018 .

LOPES, M. C. Melhoria de Processo sob a Ótica do Lean Office. Monografia (Graduação em Engenharia de Produção Mecânica) - Universidade de São Paulo, SP, 2011

MARCHINI, D.; FERNANDES, G.; SANTOS, R.; SILVA, I.; LIMA JR, O. Uma revisão sistemática sobre práticas do Lean Service, Em XIX Simpep, 2012.

OHNO, T. O Sistema Toyota de Produção - Além da produção em larga escala. Porto Alegre: Artes Médicas, 1997.

OLIVEIRA, J. D. Escritório Enxuto (Lean Office). São Paulo: Lean Institute Brasil, 2012. Disponível em:<http://www.lean.org.br/artigos/57/escritorioenxuto-(lean-office).aspx >. Acesso em: 20 de novembro de 2017.

OLIVEIRA, P. Aplicação do Lean Manufacturing na Indústria das Embalagens Plásticas - Um estudo de caso. Universidade Fernando Pessoa, Porto, 2011.

PLANEJAMENTO ESTRATÉGICO DA REDE 2016-2018, Brasil Júnior. Disponível em: <https://issuu.com/brasiljunior/docs/planejamento_estra t_gico_da_rede_2> Acesso em: 03 de junho de 2018 .

PORTAL ADMINISTRAÇÃO. Consultoria Empresarial: Conceitos e Etapas, 2015. Disponível em: $<$ http://www.portaladministracao.com/2015/01/consultoria-empresarialconceito-e-etapas.html > Acesso em: 02 de junho de 2018.

RIANI, A. Estudo de Caso: O Lean Manufacturing aplicado na Becton Dickinson. Universidade Federal de Juiz de Fora,
Minas Gerais, 2006.

ROMAN, D.; MARCHI, J.; FORCELLINI, F.; ERDMANN, R. Lean Service: Aplicação do Mapeamento do Fluxo de Valor em uma organização de serviços. Universidade Tecnológica Federal do Paraná - UTFPR, Revista Gestão Industrial, Ponta Grossa, 2013.

ROTHER, M.; SHOOK, J. Aprendendo a Enxergar, São Paulo: Lean Institute Brasil, 1999.

ROTHER, M.; SHOOK, J. Aprendendo a Enxergar, São Paulo: Lean Institute Brasil, 2003.

SILVA, C.; ZILBOVICIUS, M.; PEDRO, M.; AZEVEDO, M.; POLO, E. Lean Thinking nas EPP's (Empresas de Pequeno Porte) do Segmento Vestuário, 2008.

SOUZA, V. Lean Thinking: Proposta para melhoria das práticas de licitações em obras públicas. Faculdade de Tecnologia - Universidade de Brasília, 2016.

SUM, F. Lean e a Melhoria de Processos de Backoffice: Implantação de Ferramentas Lean no Gerenciamento de um CSC. Dissertação (Pós-Graduação em Engenharia de Produção), UFRS. Porto Alegre, 2016.

TERSE, C.; ARAUJO, L. Lean Office: Sistematizando filosofia, conceitos e práticas dos escritórios enxutos, 2017. XX Semead, Seminários em Administração.

VÁSQUEZ, F.; LÓPEZ, M. Una Revisión Crítica a Lean Service. Revista Espacios, 2018.

WERKEMA, C. Lean Seis Sigma: Introdução às ferramentas do Lean Manufacturing, 2 ed. Campus, 2012.

WOMACK, J. P.; JONES, D. T. Lean thinking: Banish waste and create wealth in your corporation, New York: Simon \& Schuster, 1996.

WOMACK, J.P.; JONES, D.T. A Mentalidade Enxuta nas Empresas, 4 ed. Rio de Janeiro: Campus Ltda, 1998.

WOMACK, J. P; JONES, D. T.; ROSS, D. A MÁQUINA QUE MUDOU O MUNDO: Baseado no estudo do Massachusetts Institute of Techonology, Trad. Ivo Korytowski. Rio de Janeiro: Elsevier, 2004, $4^{\text {a }}$ reimpressão. 